U.S. citizens, funding for collaborative programs), but it was not generally known that there was an "international" program that addressed some aspects of this type of funding.

\section{Commentary and \\ Recommendations}

The materials science community as represented by the participants in these focus groups has a very poor understanding of the overall mission of NSF and of DMR in particular. It also knows little about available programs or about the review and funding process. Education on programs would increase applicant pools, and could lead to increased levels of quality of submissions. It also would help fulfill some NSF goals of supporting the equitable development of a high quality science, engineering, and mathematics infrastructure.

Education on the review and funding process also appears to be important. This will be particularly important if NSF/DMR chooses to launch new review criteria. The rationale and context for the criteria will need to be made clear, both to the proposing and reviewing communities. Furthermore, if DMR wishes to have substantive reviews of the "broader impact" criterion or one similar to it, it will have to invest significantly in education of reviewers and of proposers.
There also may need to be additional training, monitoring, or some other addition of rigor into the proposal and review process if NSF/DMR wishes to be accountable to its published criteria. Although these focus groups were not the appropriate forum in which to pursue discussions about how reviews are actually done, it sounded like there was a great deal of variability in the application of the criteria. A set of focus groups populated by experienced reviewers might yield some insight into preferred and most useful processes, and methods for enhancing the rigor of the processes.

NSF may consider instituting some practice allowing interaction among proposers and reviewers before final funding decisions are made. This would give proposers an opportunity to rebut criticisms or clarify misunderstandings, and was felt by participants in these sessions to be a critical missing element of the current process.

NSF / DMR might consider a process modification that involves a short white paper submission followed by a longer proposal on a subset of that pool. Again, targeted focus groups on preferred processes would yield useful information.

The institution of a formal deadline and modification of the review process to allow or encourage comparative reviews would be seen as positive changes by materials scientists.

Finally, NSF/DMR might consider it useful to collaborate with a group such as MRS to explore in depth the actual activities that take place during the review process. How do reviewers use the criteria (some comments received here indicated that they are not used at all)? What additional information does a reviewer find useful to the review process to augment that which is presented in the written proposal (the reviewer's peers' knowledge of the proposer, for example)? Is there some format other than the current one that would be more helpful to the reviewer? The answers to these and other questions might help DMR design a review process that is not only more efficient but more effective in achieving its goals.

As a closing note, although MRS chose the demographic criteria it did to be "most representative" of MRS, it might have been able to address specific issues better if it had discriminated by some measure of experience with NSF. However, many of the questions could be answered by any member of the materials science research community, and NSF did get feedback on the visibility of and knowledge of the community about its programs and processes.

JESSICA GLICKEN ECOLOGICAL PlanNING AND TOXICOLOGY, INC.

\title{
MRS Seeks Graduate Student Award Applications for 1997 Fall Meeting
}

The Materials Research Society Graduate Student Awards are intended to honor and encourage graduate students whose academic achievements and current materials research display a high order of excellence and distinction. Awards are presented to students who demonstrate excellence in their materials research projects and show promise for future substantial achievement in the field.

To be eligible for the award, applicants must have good standing in a recognized academic graduate degree program or have received their final research degree within the four months prior to the meeting. They must participate in the 1997 MRS Fall Meeting in Boston as the author or co-author of a paper and be prepared to participate in the finalists' student presentation judging session, which is held during the meeting.

The selection of the recipients is completed in two steps. First, a group of finalists is identified on the basis of information provided in the award applications. Second, each finalist presents a 10-minute talk in a special student presentation judging session at the meeting.
The recipients of the award will be announced at an Awards Ceremony during the meeting and announced in $M R S$ Bulletin. Each award consists of a $\$ 250$ cash prize, payment of the registration fee for the meeting, and a presentation plaque.

The application deadline is August 29, 1997. For information and an application form, contact John B. Ballance, Executive Director, Materials Research Society, 9800 McKnight Road, Pittsburgh, PA 152376006; 412-367-3003; fax 412-367-4373; or http:/ / www.mrs.org/awards/Gradstud. html/.
1997 MRS Fall Meeting December 1-5, 1997 Boston, Massachusetts
PREREGISTRATION DEADLINE: NOVEMBER 14, 1997.

To Preregister, call 412-367-3003

HOTEL RESERVATION DEADLINE: NOVEMBER 1, 1997

Boston Marriott/Copley Place: 617-236-5800; fax 617-236-5885

Westin Hotel/Copley Place: 617-262-9600; fax 617-424-7483

Sheraton Boston Hotel and Towers: 617-236-2020; fax 617-236-6095

A roster of alternative hotels is available from MRS Headquarters, fax 412-367-4373; e-mail info@mrs.org. 